\title{
Eficiencia de la Normativa Penal Ecuatoriana: Análisis Económico de los Delitos Menores
}

\author{
Efficiency of the Ecuadorian Criminal Law: Economic \\ Analysis of Misdemeanors
}

\author{
Ab. Michelle Estefanía Cárdenas Vargas \\ Investigadora Jurídica, Suárez \& Sánchez Abogados \\ Artículo Original (Revisión) \\ RFJ, No. 3, 2018, pp. 37-59, ISSN 2588-0837
}

RESUMEN: este documento introduce el análisis económico del Derecho Penal, específicamente de los delitos menores en el Estado ecuatoriano; se enfoca en un estudio teórico de las circunstancias que motivan al delincuente a cometer actos ilícitos e incurrir en la comisión de delitos menores, las penas contempladas como sanción de estos actos y el costo que representa para el Estado la existencia de este tipo de contravenciones. El enfoque del estudio parte de las herramientas otorgadas por la microeconomía para indicar la responsabilidad del sujeto que comete delitos menores y la respuesta del Estado ecuatoriano frente a este tipo penal, con el fin de mejorar las políticas públicas y de este modo conseguir el bien social.

PALABRAS CLAVE: derecho penal, delitos menores, contravenciones, costo-beneficio, incentivos.

ABSTRACT: this paper develops and indicates the economic analysis of criminal law, specifically misdemeanors in Ecuador. It focuses on a theoretical study of the circumstances that motivate the offender to commit unlawful acts and incur the commission of minor offenses, the penalties referred to as a sanction for these acts and the cost to the state. The document is focus on a study of law based on microeconomics science to indicate the responsibility of the subject who commits minor offenses, how the country responses to these actions and the way it tries to avoid offenses improving public policies.

KEY WORDS: criminal law, minor offences, contraventions, costbenefit, incentives. 


\section{INTRODUCCIÓN}

El objetivo del artículo es realizar una revisión teórica a partir de lineamientos de análisis económico del Derecho Penal, con el fin de entender la conducta detrás del cometimiento de delitos menores en el Ecuador. En ese sentido, se aplicarán supuestos metodológicos de la economía del Derecho considerados idóneos para establecer y conocer la estructura, procesos e impactos económicos de la ley y de otras instituciones (reglas) legales. A partir de lo expuesto, se asumirá que el objetivo del análisis económico de los delitos menores será describir el impacto (oportunidades percibidas) que una norma tiene sobre el individuo y si el contenido de la misma entendida a manera de costo potencial tiene incidencia o no en la realización de una conducta entendida por el ordenamiento como "antijurídica".

Además, en el artículo las contravenciones e infracciones serán entendidas como aquellas acciones que consisten en ilícitos considerados como meros actos de desobediencia, que consecuentemente afectan la paz social y el bien jurídico protegido. El estudio de este tipo de delitos se enfocará en la responsabilidad penal y cómo esta interactúa con la economía a través de la creación de políticas públicas y la consideración de su grado de eficiencia social.

En cuanto a la propuesta metodológica, se recopilarán publicaciones jurídicas de autores nacionales e internacionales con la finalidad de establecer el nivel del alcance conceptual. El problema radica en que en Ecuador no se ha realizado un análisis económico jurídico de los delitos menores frente a las normas legales existentes, por esta razón es necesaria esta investigación y análisis; además, se debe revisar la teoría del contenido de dichos delitos, su importancia y relevancia para la sociedad. Después de realizar la recolección y estudio de datos, se analizará su relación con la realidad del Ecuador en referencia a la información encontrada. Adicionalmente, en el documento se desarrolla una introducción histórica del análisis económico del derecho penal, posteriormente el desarrollo del tema de infracciones y delitos menores, eficiencia de la norma, las causas que provocan la comisión de delitos y las penas sancionatorias de estos. Se aplica la metodología previamente descrita con el objetivo de investigar el impacto económico de la ley y del derecho penal, en la comisión de delitos menores. 
Se pretende también conocer el contenido teórico de los delitos menores dentro del Estado ecuatoriano, indagar los preceptos del análisis económico del Derecho Penal para que de este modo se logre elaborar un documento en el que se evidencie la realidad económica del cometimiento de los mismos del Ecuador.

\section{HISTORIA DEL ANÁLISIS ECONÓMICO DEL DERECHO PENAL}

La Economía tiene una relación con el Derecho, esto se establece desde la discusión hobbesiana sobre la propiedad en el siglo XVII. El análisis económico del Derecho resurgió en la década del 60, en el que Bentham tuvo un papel importante e influyente referente al análisis económico del Derecho y su doctrina.

Aquellos que no son economistas tienden a asociar a la Economía con el dinero, el capitalismo, el egoísmo, una concepción reducida e irreal de la motivación y el comportamiento humano. (Posner, R. 2002)

Denominado en los términos de la cultura anglosajona como law and economics el análisis económico del Derecho define un campo de aplicación de la teoría económica (principalmente la Microeconomía y las bases conceptuales de la economía del bienestar) al examen de la formación, estructura, procesos e impactos económicos de la ley y de las instituciones jurídicas.

Cabe destacar que todo comportamiento humano acarrea consecuencias de carácter económico, ya sea directa o indirectamente, sin ser una excepción el Derecho Penal y por estas razones merece ser analizado a partir de las herramientas proporcionadas por la ciencia económica.

La historia del Derecho Penal presenta un largo recorrido, actualmente se pretende ir más allá de conceptos, por esta razón es necesario realizar investigaciones jurídicas, penitenciarias, sociológicas e históricas de esta rama del Derecho; situación que produce el agrandamiento de la ratio penal. 


\section{ANÁLISIS ECONÓMICO DEL DERECHO PENAL - DELITOS}

La teoría del crimen puede ser analizada desde la perspectiva económica, en este caso, se desarrolla sobre la comisión de delitos menores en el Ecuador. Es importante establecer que el delito, antes de ser objeto esencial del Derecho Penal, se entiende como un fenómeno social, y por esta razón ha sido interés de estudio de otras ciencias sociales además del Derecho. (Barroso, J. 2015).

En 1968 Becker publicó el artículo "Crime and Punishment: An Economic Approach" en él presentó una visión completamente nueva del comportamiento criminal. La obra es uno de los puntos de partida de la teoría económica del delito, que ofrece un modelo que pretende predecir el comportamiento delictivo y establecer un objetivo para el Derecho Penal. La teoría del comportamiento delictivo sostiene que el delincuente compara el beneficio de cometer un delito con el costo o daño que supone el castigo esperado establecido por la normativa en materia penal.

Mercado, P. (1994), indica que existe la posibilidad de valorar en el campo económico bienes y fenómenos no mercantiles o patrimoniales, frente a esto Becker señala que los comportamientos humanos son producto de la sociedad económicamente establecida, situación que es aplicable en los casos de cometimiento de delitos; este comportamiento es el resultado del medio que lo rodea y de la economía coyuntural. Es necesario acotar que todo accionar humano lleva un costo implícito y por lo tanto no existe actividad desarrollada por una persona que no se vincule con un valor económico.

El delito es la infracción de una norma jurídica.; frente a este, se encuentran los medios para combatirlo. Según Funes, M. (1953), el instinto de conservación y de lucha se constituyen en medios para atacar el delito; esto debido al predominio de la esencia primitiva del hombre, lo cual se podría considerar que evita el progreso de la cultura en la actualidad.

La existencia de una considerable cantidad de tipos penales se considera como un problema en la rama del Derecho relativo a esa materia, esto debido a la cantidad de bienes tutelados, extendiendo así el campo de investigación del tema de delitos convencionales y su estudio económico, puesto que es necesario establecer la efectividad 
de la norma frente a los mismos y si la pena que conlleva este tipo de infracciones es justa y eficaz.

Dentro del delito se encuentran elementos constitutivos y elementos esenciales, la ausencia de estos provoca la inexistencia del delito, mientras que las atenuantes y agravantes no afectan directamente al delito ya que se refieren exclusivamente al cálculo de la pena y la severidad de la misma de acuerdo a los hechos y circunstancias referentes a la comisión del delito. (Nieto, A. 2013)

Es evidente que la ley y la economía interactúan en formas distintas, a través de este análisis se pretende indicar y destacar la convergencia del Derecho Penal y la Economía, específicamente en el ámbito de los delitos menores y la eficiencia de las políticas públicas existentes para este enfoque.

El Derecho Penal busca la protección del bien jurídico, entendido como aquel objeto cuya tutela penal está justificada y por lo tanto las leyes lo amparan. El objeto del delito debe ser necesariamente un derecho subjetivo natural de la persona. En este punto entra el poder punitivo del Estado para proteger el bien jurídico y en caso de vulneración del mismo, sancionarlo, lo que constituye una relación entre el Estado y ciudadano y poder - libertad.

\section{INFRACCIONES Y DELITOS MENORES}

El Derecho es una ciencia social sujeta a grandes cambios, puesto que evoluciona con la sociedad. En el caso del Derecho Penal, este abarca una cuidadosa selección de bienes jurídicos protegidos. El texto punitivo se basa en un pensamiento técnico-criminal, en el que se establecen delitos menores como contravenciones e infracciones.

Según Ferrajoli, L. (1992), se conoce como delitos menores o contravenciones a aquellos que consisten en infracciones de poca monta o en meros ilícitos de desobediencia. Por su parte, Luis Rodríguez Manzanera expone que el delito es "la acción u omisión que castigan las leyes penales, es la conducta definida por la ley".

$\mathrm{Al}$ analizar económicamente al Derecho Penal, específicamente a los delitos menores, se busca obtener resultados que demuestren el costo de la comisión de los mismos dentro del Ecuador. Se debe señalar que el 
coste no es de mercado, sino que se enfoca en la responsabilidad, leyes y consecuencias de los mencionados delitos. (Favoreu, L. 1999).

En Ecuador, las sanciones para la comisión de delitos menores incluye penas privativas de libertad, situación que significa una gran inversión del Estado para proteger el bien que ha sido vulnerado.

Es importante considerar que el análisis económico del Derecho Penal, parte del supuesto que la persona que comete delitos es racional como todos los seres humanos, esta situación se estudia mediante el uso de herramientas económicas que establecen la reacción del delincuente frente a la norma existente, de este modo se evidencia la eficiencia de la ley al tipificar los delitos (menores).

Es necesario mencionar que existen diferentes niveles de penas, así como grados de culpabilidad y responsabilidad, criterios que son necesarios para llegar a una pena justa, ya que se requiere que la pena sea congruente con el delito y respete el debido proceso, criterio que debe considerarse al momento de aplicar una acción sancionatoria por la comisión de delitos menores.

Asimismo, Hassemer, W. (1998), presenta una propuesta diferente al separar el nuevo Derecho Penal con respecto a las contravenciones. Esta teoría, pretende despenalizar el derecho pero no administrativizarlo, propone una rama nueva de la ciencia jurídica, identificada como "Derecho de Intervención".

El jurista establece que el Derecho Penal moderno rompe las construcciones dogmáticas del Derecho Penal clásico; su finalidad consiste en modernizarlo y permitir la extracción de "determinados tipos y, conjuntamente con ilícitos que no son penales pero que pertenecen al ámbito jurídico sancionatorio, por ejemplo, las contravenciones, y de este modo se cree un derecho nuevo, el "Interventionsrecht". Este derecho de intervención según Hassemer, W. (1998) "se situaría entre el Derecho administrativo sancionador (básicamente el derecho de contravenciones o de ilícitos administrativos) y el Derecho Penal". 


\section{EL DELITO COMO ACTO INEFICIENTE}

El análisis económico de los delitos menores se basa en la teoría consecuencialista, que indaga en el cometimiento de este tipo de fenómenos jurídicos penalmente relevantes, reconoce que el delito es aquel acto socialmente indeseable y que produce consecuencias dañinas, por lo tanto su perjuicio es mayor que el beneficio social, hecho que establece la importancia y necesidad de buscar las medidas para evitarlo.

El delito se constituye como un hecho ineficiente porque no beneficia a la sociedad, según Sánchez, J. (1996), "se caracteriza por la transferencia puramente coactiva de riqueza realizada al margen del Estado". Situación que tiene concordancia con lo establecido en la legislación ecuatoriana indica que el delito es la conducta típica y antijurídica, es decir contraria a la norma. Este precepto se fundamenta en el principio mallum actionis que indica que si el delito fuera beneficioso no sería necesario evitarlo ni sancionarlo por lógicas razones.

En referencia a esta postura, Posner, R. (2002), indica que la economía es la ciencia de la elección racional, trata de conseguir su propio interés en la mayor medida posible, situación que corresponde a incentivos. Dentro de este punto se analiza el Derecho Penal a partir de la ciencia económica, se establece que los sujetos que cometen delitos son racionales y para su actuar realizan cálculos de costo beneficio de cada acción para así establecer su eficiencia.

Una vez realizado este análisis de costo beneficio la persona decide si comete o no el delito, depende también de las circunstancias que lo rodean y modifican su decisión. Según Shavell, "un sujeto comete un delito si la sanción esperada es menor a los beneficios privados esperados de la comisión del acto”. (Sánchez, J. 1996).

Son los precios (monetarios o no) los que llevan a las personas a esos equilibrios y que el orden jurídico tiene la virtualidad de imponer sanciones y restricciones capaces de afectar los incentivos individuales al momento de tomar decisiones. (Rojas, R., Schenone, O. y Stordeur E. 2012).

En aquellas economías con elevados grado de educación, salario real, y productividad marginal del trabajo, los agentes poseen una utilidad de reserva alta, y como además generalmente la justicia ejerce un rol eficaz, el incentivo a cometer crímenes es muy bajo, o se cometen pocos crímenes pero de alto valor económico. (Milei, J. G. y Gabilondo, 1999). 
Por tanto el individuo decide sí comete o no un acto ilícito de acuerdo con el beneficio que puede recibir y solo si la sanción no es mayor al incentivo que recibe. En este punto los delitos menores o contravenciones no provocan conmoción social y son de poca monta por esta razón se debe conocer que es lo que motiva su comisión y si el beneficio es efectivo como para inferir en dicha acción.

\section{Delitos menores o contravenciones dentro de la legislación ecuatoriana.}

El Código Orgánico Integral Penal engloba a la normativa sustantiva y adjetiva de la materia en Ecuador; dentro de este se encuentra establecido el catálogo de delitos y por lo tanto las contravenciones (delitos menores) y sus sanciones. Existen cuatro clases de contravenciones en referencia a su gravedad y sanción, además se incluye una sección enfocada en las contravenciones que ocurren en escenarios deportivos y de concurrencia masiva.

Las sanciones para las contravenciones van desde trabajo comunitario hasta sanción privativa de la libertad de treinta días, depende de la clase a la cual pertenece y se incluye la prohibición de ingreso a todo escenario deportivo y de concurrencia masiva hasta un año.

A partir de lo establecido en el Código Orgánico antes mencionado, nace la interrogante de conocer la razón por la cual se puede incidir en la comisión de delitos menores si la sanción se concibe como mayor a cualquier tipo de beneficio al que pueda aspirar el sujeto que infringe la ley, si bien el incurrir en contravenciones perjudica directamente a su autor y se basa en acciones que pueden ser evitadas simplemente cuando se presta la atención debida y discernir acerca del incentivo, que para el caso es mínimo en comparación a la sanción que incluye privación de la libertad.

Con la finalidad de corroborar lo mencionado, se puede indicar que una contravención de tercera clase consiste en que "la persona que cierre las puertas de emergencia de los establecimientos de concurrencia masiva, que impidan la evacuación de personas", su sanción es pena privativa de la libertad de diez a quince días.

La decisión de ejecutar la acción depende directamente del sujeto y su raciocinio, pero cuál es el beneficio que esta persona percibe, 
esto solo lo puede responder el accionante, pero sin duda el perjuicio social es inminente. Dentro de esta relación, la interrogante sería qué incentivo recibe el delincuente o contraventor para ocasionar el daño y asumir la privación de libertad de quince días.

Un punto controversial que cabe mencionar en el presente caso es que si la sanción fuera mayor posiblemente la reacción y análisis costo beneficio del sujeto sería distinta e incluso se evite el cometimiento de dicha acción antijurídica punible, esto sucede debido a que el perjuicio se volvería mayor a cualquier posible beneficio; razón por la cual se puede llegar a determinar que el beneficio que el contraventor recibe es únicamente el hecho de sobresalir entre las demás personas, sin importar la causa, su incentivo es llamar la atención del medio que los rodea y sobresalir, pese a las consecuencias existentes.

Principalmente esta sería la lógica de quienes cometen delitos menores, puesto a que no causan mayor conmoción social y no perjudican gravemente el bien jurídico protegido por el Estado, realizan acciones contra la ley con el propósito de destacar, ya que el beneficio no es otro más que este.

\section{EL BIEN JURÍDICO PROTEGIDO}

El Derecho Penal tiene la finalidad del control social por parte del Estado con el objetivo de mantener la paz en los países garantistas. Esta rama del Derecho busca proteger el bien jurídico, entendido como los bienes materiales e inmateriales que se encuentran dentro del Estado y se encuentran amparados por el Derecho.

Para que el delito se constituya como tal, debe existir la vulneración del bien jurídico protegido. El daño irrogado afecta directamente la propiedad del bien jurídico protegido por la punición de este hecho. Al respecto, Rocco, afirma que "el que niega la existencia de un derecho subjetivo de punir al Estado, se cierra la posibilidad de comprender y fundamentar el sistema del Derecho Penal”.

En caso de vulneración de los considerados bienes jurídicos, se ejecuta el poder punitivo del Estado o ius puniendi, se lo conceptualiza como la capacidad para juzgar o derecho para castigar que tiene el Estado, es menester destacar que este es el único con facultades para conocer y decidir sobre la existencia de un delito y la aplicación de la 
pena. A partir del mismo, se organizan las relaciones entre las leyes penales y la libertad y derechos de los ciudadanos.

Respecto al ius puniendi, Ramiro Ávila (2008), sostiene que: "El poder punitivo es una de las formas de intervención en el ejercicio de los derechos humanos, que se justifica solo cuando es estrictamente necesario y cuando atenta contra bienes jurídicos que están constitucionalmente protegidos". Jorge Zabala Baquerizo indica que, "no toda conducta debe ser criminalizada al capricho del legislador, sino solo aquellas mínimas que afectan de manera grave al bien jurídico que se pretende proteger".

En el caso de infracciones y contravenciones el Estado impone sanciones cuando se altera el orden social, ya sea por acciones u omisiones cuya responsabilidad recae en una o varias personas, se busca reparar el daño ocasionado y para esto únicamente el Estado tiene la potestad de hacerlo, a través de los mecanismos que la ley le otorga.

\section{El sujeto delincuente frente al sujeto no delincuente}

El comportamiento delictivo de una persona depende directamente de su raciocinio y sus condiciones de elección frente al hecho de tomar decisiones, después de analizar el incentivo que puede obtener como lo establece Sánchez, J. (1996). Esta conceptualización se fundamenta en que el pensamiento criminológico no se basa en conocer las causas que motivan al individuo a delinquir, o si estas son naturales, adquiridas, temporales o causadas por simples impulsos.

El objetivo del análisis económico de la comisión de delitos menores es establecer que la conducta delictiva parte de la racionalidad del ser y la lógica de sus decisiones; lo que indica que entre el delincuente y otros sujetos no existen diferencias estructurales, esto significa que no se considera delincuente a un sujeto por sus condiciones patológicas ni fisiológicas. (Álvarez F. 1988).

La situación determinante para incurrir en infracciones y contravenciones es el incentivo que la persona recibe y el beneficio de este, ya que todas las personas son iguales considerándolo de forma intrínseca. Por lo tanto, la teoría económica del delito se basa en la existencia del cálculo costo-beneficio. 
En contraparte a este argumento, Radbruch manifiesta que "(...) el hombre delincuente no está en absoluto en condiciones de ponderar fríamente ventajas e inconvenientes de su conducta y elegir el camino más beneficioso para él, que más bien es preciso corregirlo, esto es, alzarlo para que obtenga su propio interés y siga su interés correctamente entendido".

Según, Galindo, L. y Catalán, H. (2007), el fenómeno de la criminalidad es complejo y cuenta con diversas dimensiones y dependen de forma negativa respecto de la probabilidad de captura frente a la severidad de la sanción. Se menciona que depende también de la tasa de desempleo.

Existen varias teorías y postulados en contra de la teoría del homo economicus, con justa razón y debidamente motivadas. Sin embargo cabe mencionar la postura de Posner al indicar que en todas las actividades que realizamos está implícito el costo de oportunidad y análisis costo-beneficio, y el cometimiento de delitos menores no es la excepción, pues implica un análisis y se limita por la pena y su severidad.

Dentro de esta teoría racional o cognitiva del cometimiento de delitos, infracciones y contravenciones; el beneficio que el sujeto que infrinja la ley se puede establecer como incentivo perverso, lo que significa que él gana a costa de otras personas que reciben el daño, en al caso de las contravenciones o delitos menores se perjudica el bien jurídico protegido

\section{FUNCIÓN DE LA PENA CONTEMPLADA POR LA COMI- SIÓN DE DELITOS MENORES}

Siempre ha sido motivo de debate y discusión la relación existente entre el acto delictivo su consecuente reacción punitiva, es decir, la pena. Son varios los criterios que se deben tomar en consideración para imponer una sanción, primero es menester indicar que un acto está sujeto a una pena cuando así lo establezca la ley, de lo contrario no existe delito; de esta forma hace alusión al axioma de derecho "nulum crime sine lege, nula poena sine lege".

Dentro del artículo 76 de la Constitución de la República del Ecuador, se consagra este principio en el numeral 3, el que señala lo siguiente: "nadie podrá ser juzgado ni sancionado por un acto u omisión que, al momento de cometerse, no esté tipificado en la ley como in- 
fracción penal, administrativa o de otra naturaleza; ni se le aplicará una sanción no prevista por la Constitución o la ley. Solo se podrá juzgar a una persona ante un juez o autoridad competente y con observancia del trámite propio de cada procedimiento".

La constante discusión referente a la finalidad de la pena hasta cierto punto ha desviado la atención sobre la materialidad de la misma. Las penas no se consideran sumamente graves o severas, dependen directamente del tipo de contravención cometida y las mismas van desde trabajo comunitario hasta treinta días de pena privativa de libertad, esto en los casos más graves.

Se debe mencionar que existen diferentes niveles de penas, para diferentes grados de culpabilidad y responsabilidad, criterios que son necesarios para llegar a una pena justa, pues es necesario que la pena sea congruente con el delito y respete el debido proceso, principio que es respetado al momento de sancionar los delitos menores.

El objetivo de las sanciones en Ecuador principalmente es la rehabilitación social de las personas (en especial de las privadas de la libertad) y su reinserción a la sociedad, pero como agentes útiles para la misma. Sin embargo, no existe certeza que esto se lleve a cabo en su totalidad, y mucho menos que de las personas reincidan en su conducta antijurídica y típica.

En otros Estados el fin de la sanción es directamente el castigo, incapacitación del delincuente y la implementación de diversos métodos de punición e incluso el aislamiento de los sujetos, pues aún se maneja la teoría de "negar" el problema para obtener una posible solución, es decir si se elimina de la sociedad al ente dañino, el problema desaparece y se regresa a un estado de armonía y paz social.

El cometer delitos a pesar de la existencia de una pena cualquiera que esta fuere, se fundamenta a base del incentivo que el potencial contraventor recibe, y de esta circunstancia depende también que el sujeto vuelva a cometer el delito o infracción.

Por lo tanto, la solución para evitar que se cometan delitos menores en reiteradas ocasiones, puede ser que la sanción sea mayor por lo que el incentivo se disminuye para el autor del delito al momento de considerar el costo beneficio de su decisión. 


\section{CATEGORIZACIÓN DE LOS DELITOS MENORES EN EL CÓDIGO ORGÁNICO INTEGRAL PENAL}

El Código Orgánico Integral Penal incluye 13 tipos de contravenciones divididos en faltas de primera, segunda, tercera y cuarta clase. Las contravenciones correspondientes a las primeras tres clases, se pueden considerar por omisiones de formalismos legales, omisión del deber objetivo de cuidado e infringir la normativa dispuesta, pero no causa mayor daño a terceros, por estas razones sus sanciones no corresponden a graves penas.

Las contravenciones correspondientes a primera clase, conllevan ínfimas sanciones que no justifica la comisión de las mismas pero con estas se evidencia la falta de rigurosidad de las penas, situación que acarrea consecuencias jurídicas negativas para la sociedad, como lo es el hecho de reincidir en las mismas.

En el artículo 396 se establecen las faltas consideradas como más graves o de cuarta clase, se indica que "será sancionada con pena privativa de libertad de quince a treinta días:

1. La persona que por cualquier medio profiera expresiones en descrédito o deshonra en contra de otra. Esta contravención no será punible si las expresiones son recíprocas en el mismo acto.

2. La persona que venda u ofrezca bebidas alcohólicas de moderación o cigarrillos a niñas, niños o adolescentes.

3. La persona que de manera indebida realice uso del número único de atención de emergencia para dar un aviso falso de emergencia y que implique desplazamiento, movilización o activación innecesaria de recursos de las instituciones de emergencias.

4. La persona que voluntariamente hiera o dé golpes a otra, causándole lesiones o incapacidad para el trabajo que no exceda de 3 días.

Édgar Ortiz, abogado en libre ejercicio, señala que las contravenciones son un tipo penal de menor afectación social, pero que obviamente no deja de existir una responsabilidad. El Código Orgánico Integral Penal, conlleva una visión diferente sobre la temática; así el citado jurista corrobora lo siguiente: "lo grave en las contravenciones es la reincidencia, violación de medidas o incumplimiento del deber objeti- 
vo de cuidado, porque su exceso conlleva a que se convierta en delitos con sanciones que superen los 6 meses".

Evidentemente, este tipo de contravenciones dañan o perturban el bien jurídico protegido, de ahí parte su gravedad a comparación de las otras clases de contravenciones, ya que su comisión puede acarrear el cometimiento de delitos como tal y por lo tanto involucra al Estado y necesita la intervención de órganos como la Fiscalía para investigar el delito en caso de incurrir en el mismo.

\section{POLÍTICA DE PREVENCIÓN Y EFICIENCIA EN LA ADMI- NISTRACIÓN DE JUSTICIA}

Milei, J. G., \& Gabilondo (1999), indica que al aumentar la inversión, en este caso, destinada a promover la seguridad, se garantiza el eficiente manejo de los recursos que promueven la disminución de los índices de criminalidad por lo tanto el resultado debe ser la disminución de la criminalidad.

Es necesario crear una cultura preventiva para evitar hechos ilícitos que configuren tipos penales, especialmente en cuanto se refiere a contravenciones porque el incurrir en estas puede conllevar a la comisión de delitos con sanciones más rígidas.

La prevención según Anselm Von Feverbach, “ es una intimidación o coacción sicológica respecto de todos los ciudadanos, pues las personas al observar la aplicación de la pena a sus semejantes que han delinquido tendrán temor de cometer acciones antijurídicas, pues su accionar traerá como consecuencia una acción más grave”. (Citado en Strang, H. y Sherman, L.W. 2003)

Referente a las contravenciones, el método de prevención pertinente es el denominado "especial", esta teoría indica que "la finalidad de la pena está dirigida a influir sobre el agente de manera directa y por ende individual". Esta teoría es llevada a su máxima expresión por Von Liszt, F. y Rivacoba, M. (1984); que indican la función preventiva especial de la pena a base de la intimidación dirigida a los delincuentes ocasionales que no necesitan corrección (contraventores).

Basándose en la teoría que los individuos son seres racionales y presentan aversión al riesgo, el Estado mediante sus políticas debe afectar 
los incentivos que pueden provocar la comisión de contravenciones (delitos menores), este se puede llevar a cabo por medio de la aplicación de sanciones fuertes y relativas a la contravención, como son: multas, trabajo comunitario y sentencias con pena privativa de libertad.

El gobierno se beneficia directamente de la utilización de diferentes medidas sancionadoras, dado que su aplicación reduce notablemente la inversión al sistema carcelario y su mantenimiento. La forma de prevención de delitos en el Estado, primordialmente respeta los principios de legalidad, necesidad social de la intervención penal y básicamente el límite que confiere el respeto a la dignidad humana, igualdad y participación de los ciudadanos, puesto que el Estado y la sociedad en conjunto deben fomentar y fortalecer la cultura preventiva.

\section{COSTO Y PROCEDIMIENTO DE LOS DELITOS MENORES EN ECUADOR}

Los delitos menores o contravenciones en Ecuador se encuentran contemplados a partir del artículo 603 del Código Orgánico Integral Penal, es menester indicar que las infracciones o contravenciones no son consideradas como delitos propiamente dichos, sino como infracciones menores por las características que los componen y por su naturaleza de ser de poca monta, pero que en definitiva son sancionables.

El proceso de juzgamiento de los delitos menores es considerablemente menor al proceso penal en otros delitos, se realiza una audiencia en la cual no se exige la presencia de un fiscal, ya que no se necesita mayor investigación o indagación de los actos cometidos; en el caso que el sujeto contraventor no cuente con un abogado que le patrocine la defensa de manera particular, el Estado es el encargado de designarle un defensor público con la finalidad de garantizar todos sus derechos dentro del procedimiento, situación que sin duda significa inversión por parte del Estado.

La sanción correspondiente es determinada por el juez dentro de la audiencia, para establecer la pena se considera el grado de la contravención, las mismas van desde el monto de cuatro hasta quince dólares americanos y pena privativa de libertad de hasta treinta días por el cometimiento de las contravenciones más graves que establece la norma sustantiva. 
Referente al tema, Rodolfo Navarrete, Juez de la Unidad de Flagrancias del cantón Quito, considera que el Código Orgánico Integral Penal (COIP) "elimina un sin número de contravenciones que están en letra muerta, contempladas en Códigos anteriores, principalmente debido a que muy pocas se juzgan o llegan a ocurrir". El hecho de mejorar y reformar una normativa penal implica un mejor manejo de la justicia, además de garantizar la eficiencia y eficacia de la misma, debido a que de esta manera los delitos menores están en concordancia con la realidad de lo que sucede en el país y aquellas contravenciones extratemporales se derogan, situación que conlleva beneficios para la legislación del Estado.

Las contravenciones que más llegan a la Unidad de Flagrancias tienen que ver con escándalos en la vía pública, violencia intrafamiliar y faltas de palabra y obra a la autoridad, principalmente porque son situaciones que se presentan en todo estrato social y sus causas son muy comunes.

Cabe mencionar que las contravenciones se cometen también debido al desconocimiento de la existencia de una sanción para las mismas, sin embargo se respeta la máxima de derecho que establece que "el desconocimiento de la norma no exime de culpa".

En cuanto al monto de la pena, el mismo se compone de dos elementos. El primer elemento es el valor de las pérdidas marginales asociadas al delito cometido sobre la probabilidad de ser capturado, más un segundo elemento dado por el cociente entre la cantidad de delito cometido sobre la variación de la cantidad de delito ante cambios en las penalidades. (Milei, J.G. y Gabilondo, M.P. 1999)

Este resultado sugiere que el monto de la pena debe ser ampliamente mayor a la cantidad de delito asociado, para que de esta forma la lógica del delincuente le permita decidir si el beneficio es mayor a la pena, o viceversa, y de esta forma se puede evitar incurrir en delitos menores.

\section{PENAS ALTERNATIVAS A LA PRIVACIÓN DE LA LIBERTAD}

El Código Orgánico Integral penal, establece penas o sanciones alternativas a la privación de la libertad del sujeto contraventor, como lo es el trabajo comunitario, se considera con esta denominación a toda "acción realizada por el delincuente a fin de hacer de la pérdida su- 
frida por la víctima algo bueno", según Baker (1994). Este concepto pertenece al tipo de justicia considerada como restaurativa.

El servicio comunitario puede ser una sanción reparadora que vincule la naturaleza del servicio con el delito a ser sancionado, puede ser una sanción positiva que despierte en el delincuente responsabilidad por sus actos y, puede reducir la carga del sistema carcelario (Wachtel, T. 2013.).

Se debe considerar la diferencia existente entre los conceptos de restitución y reparación, a fin de comprender el objetivo del trabajo comunitario; la restitución repara el daño causado a la víctima particular, mientras que el servicio comunitario repara el daño a la comunidad en general, proveyéndole de un beneficio.

El servicio comunitario se constituye potencialmente como un tratamiento alternativo, concepto que va más allá de una alternativa de sanción, según lo entabla Walgrave. La orden de servicio indicada con frecuencia se adecua al delincuente y no al delito, el servicio comunitario se usa primordialmente a fin de rehabilitar al delincuente, sus motivaciones respecto de la reparación se tornan secundarias. (Citado en Watchel, T. 2013)

De este modo se fomenta que el delincuente o contraventor analice profundamente qué es lo que obtiene al infringir la ley, afectar el bien común y a la paz social, debe discernir su costo beneficio y el de transacción, es decir, si tiene mayor valor lo que pierde o aquello que obtiene como consecuencia de sus acciones. El servicio comunitario tiene como fin la reflexión por parte del contraventor sobre sus actos y no vuelva a cometer los mismos.

Esta es una visión que permite el comienzo de un modelo nuevo referente al tipo de rehabilitación, "con lo cual se evitará que las cárceles se llenen de contraventores y se adopte una reparación a la falta cometida con la ayuda social" según explica el juez Rodolfo Navarrete. .

El beneficio es evidente para toda la sociedad, aporta en la economía del Estado porque permite que los centros penitenciarios no se encuentren abarrotados de personas que cometen delitos menores, situación que también beneficia a los contraventores, puesto que, el hecho de estar en una cárcel le puede acarrear condiciones traumáticas y dañarlo de forma emocional, debe considerarse que este tipo de 
centros en Ecuador deben avanzar y desarrollarse notablemente para cumplir con su finalidad de rehabilitación social.

Según una serie de estudios e investigaciones realizadas en varios países, a partir del año 1986 hasta el 2005 a cargo de Heather Strang y Lawrence Sherman, se llega a establecer "que la Justicia Restaurativa reduce la reincidencia sustancial para un grupo de ofensores, y la reduce más que la prisión o tanto como la prisión en otros casos".

Sin embargo esta característica positiva no es aplicable en la generalidad de los casos, depende de las características particulares e intrínsecas del sujeto contraventor, razón por la cual no es efectiva del todo, es decir tienen sus excepciones pero el beneficio es superior.

Este tipo de justicia alternativa permite una mayor posibilidad de reinserción a la sociedad que los casos de justicia penal convencional y pena privativa de libertad. Por lo tanto, el costo beneficio de esta sanción alternativa es mayor a la que acarrea la pena privativa de libertad, en consideración del bien común tanto para los ciudadanos como para el Estado ecuatoriano.

\section{CONCLUSIONES}

La teoría del comportamiento delictivo, en este caso enfocada en la comisión de delitos menores según la normativa ecuatoriana, establece que el delincuente, en este caso el contraventor, es un sujeto completamente racional y que para incurrir en un delito debe razonar lógicamente su decisión.

Mediante el estudio realizado, se llega a determinar que el contraventor compara el beneficio que obtiene al cometer un delito frente al daño o costo que conlleva esta acción, es decir, analiza el incentivo existente como consecuencia de su accionar. En caso que el daño o perjuicio sea mayor que el incentivo, el sujeto no cometerá la contravención o delito menor por obvias razones, entre estas, por el hecho que todo ser humano actúa para mejorar y obtener resultados que lo beneficien positivamente.

Los delitos menores en el Estado ecuatoriano abarcan el concepto de contravenciones, se instituyen como infracciones de poca monta y tiene diferentes formas de sanción, incluye penas pecuniarias, méto- 
dos alternativos de sanción como lo es el trabajo comunitario y en los casos más graves conlleva a una pena privativa de libertad de hasta treinta días, en relación con el acto incurrido, debido a que la sanción es proporcional a la falta.

La norma jurídica en Ecuador que establece cuales son los delitos menores y su sanción, es el Código Orgánico Integral Penal, dentro del mismo se establecen las clases de contravenciones, son de primera clase las más leves hasta llegar a cuarta clase las más graves.

Es menester indicar que en el documento se cumple con los objetivos propuestos y evidencia la realidad sobre el análisis económico del Derecho Penal aplicado en la comisión de delitos menores, y se comprueba que las penas alternativas, tales como las que conllevan pago de multas y el trabajo comunitario produce un alto costo beneficio para el Estado, principalmente porque la inversión en rehabilitación social en centros especializados es menor.

\section{REFERENCIAS BIBLIOGRÁFICAS}

Acciarri, H. y Castellano, A. (2010). El análisis económico del derecho de daños. Responsabilidad civil.

Acciarri, H., Barbero, A. y Castellano, A. (1998). Garantías legales en la ley de defensa del consumidor; Anales de la XXXIII Reunión Anual de la Asociación Argentina de Economía Política. Mendoza, AAEP.

Alterini, A. (1991). Curso de obligaciones, tomo 2, 4ta edición. Buenos Aires, Abeledo-Perrot.

Álvarez-Uria, F. (1988). Violencia y delito: Materiales para una sociología de la violencia. Ábaco, (4), 75-89.

Auping, J., De la Torre, R., Guevara, A., Llamas, I. y Muñoz, C. (2004). El análisis económico de los derechos humanos (Primera ed.). México: Universidad Iberoamericana.

Ávila, R. (2008). Ecuador, Estado constitucional de derechos y justicia. Constitución del, 19-38. 
Barroso González, J.L. (2015). Los delitos económicos desde una perspectiva criminológica. Revista IUS, 9(35), 95-122.

Bejarano, J. (1999). El análisis económico del derecho: comentarios sobre textos básicos. Revista de Economía Institucional, vol. 1, núm. 1, noviembre, 1999. 155-167, Universidad Externado de Col. Colombia.

Bullard Gonzales, A. (2003). Derecho y Economía. El análisis económico de las instituciones legales. Editorial Palestra. Lima Perú.

Cervantes, M., Emanuelli, M., Gómez, O. y Sandoval, A. (2014). ¿Hay Justicia para los Derechos Económicos, Sociales y Culturales? (Primera ed.). México: Universidad Nacional Autónoma de México; Suprema Corte de Justicia de la Nación.

Coase, R. (1960). The Problem of Social Cost, Journal of Law and Economics, vol 3, 1.

Coloma, G. (1997). La ley argentina de defensa de la competencia; Anales de la XXXII Reunión Anual de la Asociación Argentina de Economía Política. Bahía Blanca, AAEP.

Coloma, G. (2010). Apuntes para el análisis económico del Derecho Privado argentino. Universidad del CEMA.

Congregado, E., Pomares, I. y Rama, E. (2002), Análisis económico del derecho: una revisión selectiva de la literatura reciente, Derecho y conocimiento, vol.1.

Convención americana sobre Derechos Humanos, (pacto de San José). Recuperado de: http://www.oas.org/dil/esp/tratados_B-32_ Convencion_Americana_sobre_Derechos_Humanos.htm el: 8 de noviembre del 2015

Corte Interamericana de Derechos Humanos. Página oficial de la web. Recuperado de: http://www.corteidh.or.cr/ el: 8 de noviembre del 2015.

Declaración universal de los Derechos Humanos. Recuperado de: http://www.derechoshumanos.net/normativa/normas/1948-DeclaracionUniversal.htm?gclid=CjwKEAiAgvyxBRDmuviAj67g-XQSJABTLMcHtw24T6Qm XsQa5GeLFinHThhYoPmIgpsw9NliXcdo4BoC8Y3w_wcB el: 8 de noviembre del 2015. 
Doménech, P. (2014). Por qué y cómo hacer análisis económico del derecho. Revista de Administración Pública. N. 195.

Favoreu, L. y Favoreu, L. (1999). La Constitucionalizacion del Derecho Penal y del Procedimiento Penal. Hacia un Derecho Constitucional Penal. Revista Chilena de Derecho.

Ferrajoli, L. (1992). Derecho penal mínimo y bienes jurídicos fundamentales. Revista de la Asociación de Ciencias Penales de Costa Rica, 4(5).

Funes, M. R. (1953). La Defensa Social, el Delito y el Peligro. Revista Mexicana De Sociología, 15(2), 197-209.

Galindo, L. y Catalán, H. (2007). Las actividades delictivas en el Distrito Federal / Criminal Activities in Mexico's Federal District. Revista Mexicana De Sociología, 69(3), 457-484.

García, F. y Ambos, K. (2011). Temas fundamentales del derecho procesal penal. Tomo 1. Cevallos Editora Jurídica. Quito, Ecuador.

Hassemer, W. (1998). Perspectivas del Derecho penal futuro. (trad. Anarte), en Revista Penal, núm. 1. 37 y ss.

Martín, A.N. (2013). Problemas fundamentales del cumplimiento normativo en el Derecho Penal. In Compliance y teoría del Derecho Penal (21-50). Marcial Pons.

Mendoza, S. (2013). Derechos humanos, costos y beneficios. IUS $360^{\circ}$. Recuperado de http://www.ius360.com/otro/analisis-economico-del-derecho/derechos-humanos-costos-y-beneficios/

Mercado Pacheco, P. (1994). El Análisis Económico del Derecho, una reconstrucción teórica. Editorial centro de estudios constitucionales. Madrid.

Milei, J. G. y Gabilondo, M. P. (1999). Análisis Económico de las Políticas De Prevención y Represión del Delito en la Argentina. Asociación Argentina de Economía Política.

Navarro, R., Steffen, M. y Dutto, C. (2010). Sistema interamericano de protección de los derechos humanos y derecho penal internacional. Montevideo, Uruguay: Fundación Konrad Adenauer. 
Noguera, H. (2010). Consejo de Estado vs. Corte Interamericana de Derechos Humanos en materia de reparaciones. Verbas Iuris, 102 - 103.

Posner, R. A. (2002). El movimiento del análisis económico del derecho: desde Bentham hasta Becker. THEMIS: Revista de Derecho, (44), 37-54.

Robert, F. (1995). Microeconomía y conducta. Pensar como economista. Editorial Mcgraw - Hill Interamericana. España.

Rojas, R., Schenone, O. y Stordeur, E. (2012). Nociones del análisis económico del Derecho privado. Universidad Francisco Marroquín. Guatemala - Guatemala.

Sánchez, J. M. S. (1996). Eficiencia y Derecho penal. Anuario de derecho penal y ciencias penales, 49(1), 93-128.

Schönsteiner, J, y Couso, J. (2015). La implementación de las decisiones de los órganos del Sistema Interamericano de Derechos Humanos en Chile: Ensayo de un balance. Revista de Derecho Coquimbo, 22(2). Recuperado de http://www.scielo.cl/scielo.php?pi$\mathrm{d}=$ S0718-97532015000200011\&script=sci_arttext

Strang, H. y Sherman, L. W. (2003). Repairing the harm: Victims and restorative justice. Utah L. Rev., 15.

Wachtel, T. (2013). Definiendo qué es restaurativo. Revista del Instituto Internacional de Prácticas Restaurativas.

\section{Base Legal}

Código Orgánico Integral Penal.

Constitución de la República del Ecuador (2008). 
Recibido: 09/01/2017

Aceptado: 23/05/2017

Michelle Estefanía Cárdenas Vargas: Investigadora Jurídica Suárez \& Sánchez Abogados

Correo electrónico: michelle.cardenashs@gmail.com 